Universidad de Lima

Facultad de Ciencias Empresariales y Económicas

Carrera de Economía

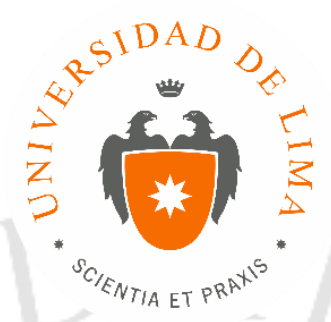

\title{
EFECTO DE LA CONTRACCIÓN DE LA OFERTA EN EL PRECIO Y CONSUMO DEL LIMÓN EN EL FENÓMENO DEL NIÑO 2017
}

Trabajo de suficiencia profesional para optar el Título Profesional de Economista

Sustentación de caso

Luis Carlos Aguilar Cruz

Código 19912010

\section{Asesor}

Elmer Sánchez Dávila

$$
\text { Lima - Perú }
$$

Diciembre de 2018 


\section{EFECTO DE LA CONTRACCIÓN DE LA OFERTA EN EL PRECIO Y CONSUMO DEL LIMÓN EN EL FENÓMENO DEL NIÑO 2017}

TABLA DE CONTENIDO 


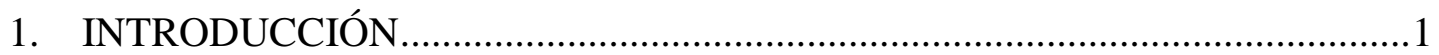

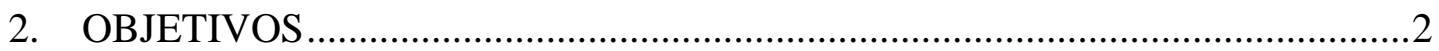

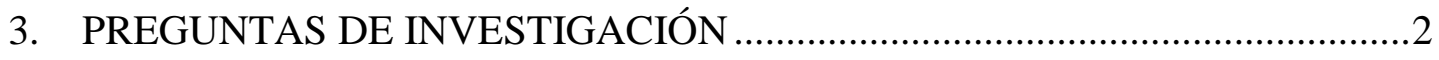

4. METODOLOGÍA DE RECOLECCIÓN DE LA INFORMACIÓN ……………....3

5. METODOLOGÍA DE ANÁLISIS DE LA INFORMACIÓN ………………….....6

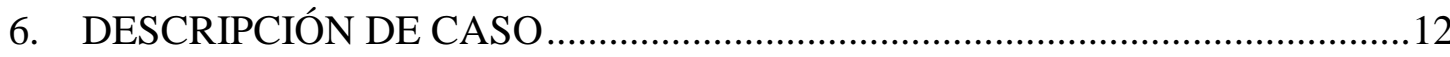

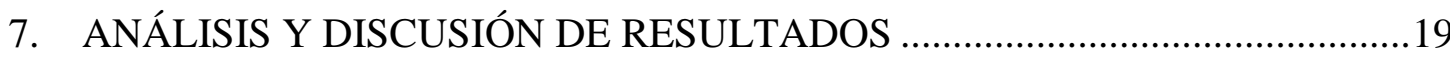

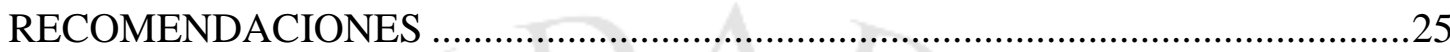

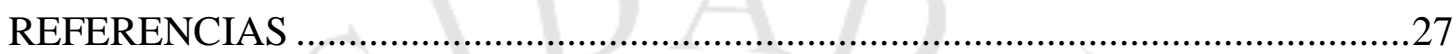

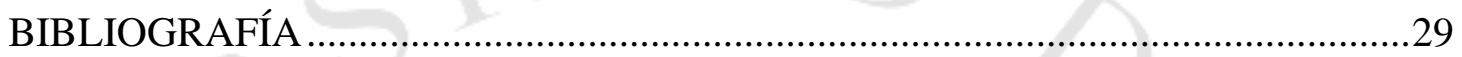




\section{ÍNDICE DE TABLAS}

Tabla 4.1 Datos del índice de precios del limón, su producción y los precios en chacra y mayorista

Tabla 5.1 Posibles resultados de la elasticidad precio de la demanda...........................9

Tabla 6.1 Cuadro de inversión en reconstrucción al 15/05/2018 …............................... 17

Tabla 6.2 Cuadro de inversión en prevención al 15/05/2018 …................................... 18

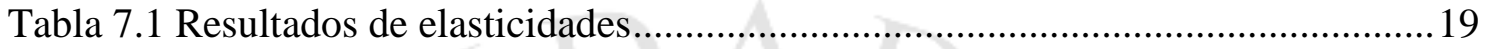

Tabla 7.2 Índice de precios al consumidor de Lima Metropolitana (Julio 2016 diciembre 2017)

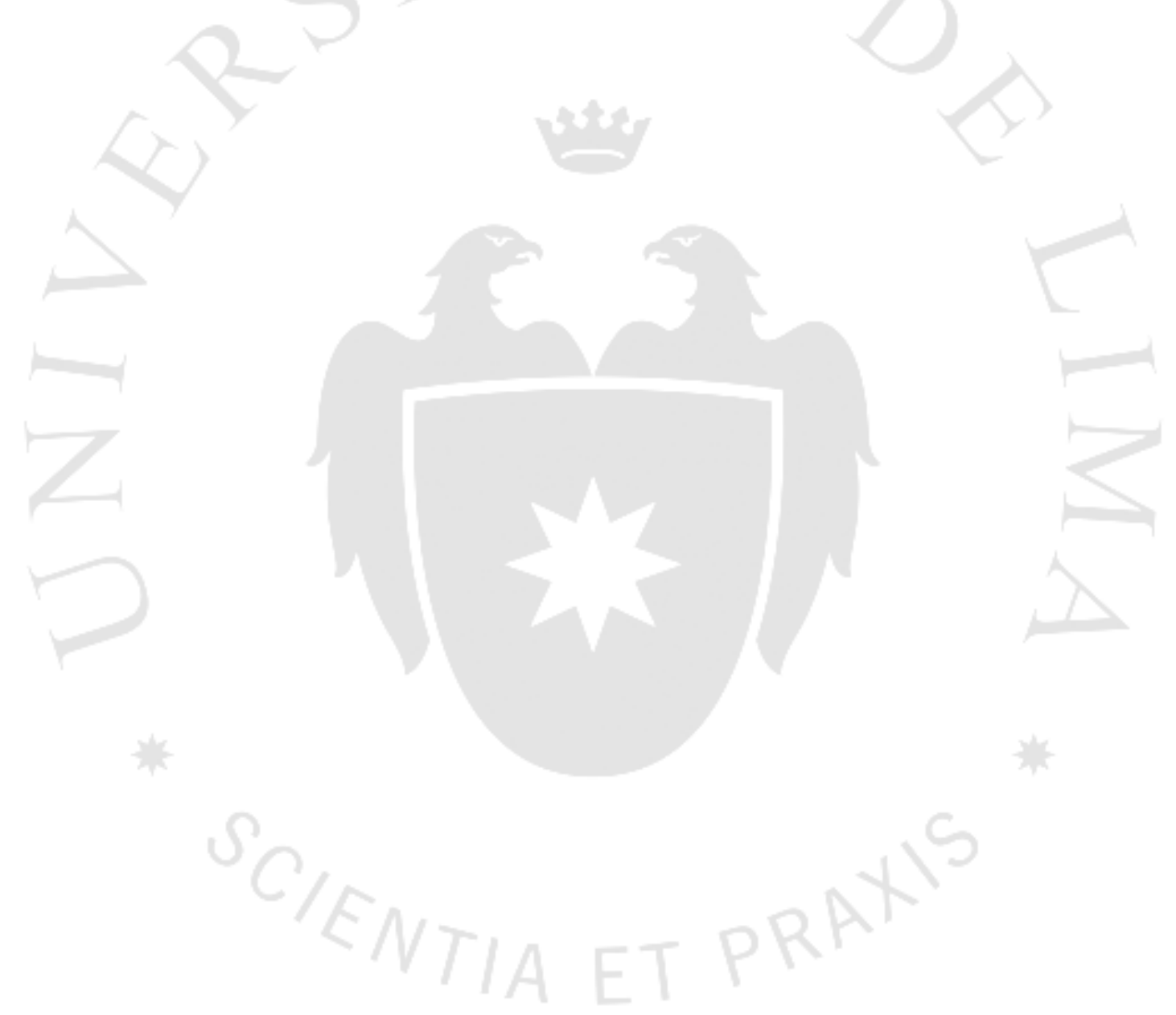




\section{ÍNDICE DE FIGURAS}

Figura 5.1 Shock del fenómeno del niño en la producción y precios del limón..............7

Figura 5.2 Demanda perfectamente inelástica: la elasticidad es igual a 0 ...................... 9

Figura 5.3 Demanda inelástica: la elasticidad es menor que 1 ................................... 10

Figura 5.4 Demanda elástica unitaria: la elasticidad es igual a 1 ................................. 10

Figura 5.5 Demanda elástica: la elasticidad es mayor que 1 .................................... 11

Figura 5.6 Demanda perfectamente elástica: la elasticidad es igual a infinito .............. 11

Figura 6.1 Ejecución financiera reconstrucción con cambios a diciembre 2017........... 16

Figura 6.2 Distribución de lo transferido en cada sector año 2017 .............................. 16

Figura 7.1 IPC y variación \% de frutas (incluido limón)............................................23 


\section{ÍNDICE DE ANEXOS}

Anexo 1: Elasticidades en valores absolutos .

31 


\section{INTRODUCCIÓN}

Desde mediados de diciembre del 2016 hasta finales de abril del 2017, Perú se vio afectado por el Fenómeno del Niño Costero el cual tuvo un impacto negativo en el sector agrícola y en la infraestructura de la costa peruana. Según estimaciones de Macroconsult (2017) el monto en pérdidas de infraestructura ascendió a US\$ 3,124 millones en daños las vías terrestres, puentes y viviendas. Según Instituto Nacional de Defensa Civil (INDECI, 2017) en el sector agrícola se vieron afectadas 131,611 has de cultivo durante el Niño Costero.

El Fenómeno del Niño ocasionó que aumenten los precios de los productos agrícolas. Al haber un choque exógeno, como lo fue este desastre natural, la curva de oferta de productos agrícolas se contrajo, lo cual explica la subida de precios de la mayoría de productos alimenticios. En esa coyuntura, el limón tuvo un comportamiento muy particular debido a que los precios minoristas se incrementaron en un 49.3\%. Al haber pocos sustitutos de este bien, los consumidores tienen dos opciones: i) seguir demandando el limón sin importar el precio (demanda inelástica) o ii) dejar de consumir el bien debido a que el precio ha aumentado y buscar sustitutos cercanos (demanda elástica). La importancia de este trabajo es determinar como la contracción de la oferta del Limón, provocado por el Fenómeno del Niño Costero, afectó el consumo del Limón teniendo en consideración los precios mayoristas y de chacra.

En 1999 el Estado peruano promulgo la Ley $\mathrm{N}^{\circ} 27245$ Fortalecimiento de Responsabilidad y Transparencia Fiscal que tendría la finalidad de tener un fondo acumulado de reservas para ser utilizadas ante eventualidades naturales. El Fenómeno del Niño Costero ocurrido recientemente obligó al Estado peruano a utilizar cerca del 29.21\% (US\$ 1,869 millones) del Fondo de Estabilización Fiscal (FEF) para la reconstrucción de la infraestructura dañada, además de crear mediante Ley $\mathrm{N}^{\circ} 30556$ la Autoridad para la Reconstrucción con Cambios. (ARCC). En la actualidad, y a más de 20 meses de ocurrido el Fenómeno del Niño Costero se puede evidenciar un mínimo avance en la reconstrucción. Según el Instituto Crecer (2018) después de más de un año de iniciado la reconstrucción con cambios es poco lo avanzado de los S/. 25,117 millones destinados solo hasta 15 de mayo del 2018 se han empleado S/. 2,481 millones los cuales se distribuyen en S/. 427 millones en Actos Previos/ En Convocatoria, S/. 239 millones contratado, S/ 965 millones en Ejecución y S. 847 millones Terminados lo 
que representa solo el $10.00 \%$ del monto destinado, es decir, solo se ha invertido un $3 \%$ en reconstrucción y $22.3 \%$ en prevención.

\section{OBJETIVOS}

\section{Objetivo General:}

Determinar el efecto del Fenómeno del Niño Costero a la demanda de Limón en el corto, mediano y largo plazo luego de ocurrido el fenómeno.

\section{Objetivos Específicos:}

- OE1. Determinar la elasticidad de la demanda de Limón en el periodo del Fenómeno del Niño Costero

- OE2. Determinar si existe alguna diferencia en las elasticidades del Limón tomando en consideración el precio promedio mensual de chacra y el precio promedio mensual mayorista

- OE3. Analizar cómo afecto los precios del Limón al Índice de Precios al Consumidor (IPC) durante el periodo del Fenómeno del Niño Costero.

\section{PREGUNTAS DE INVESTIGACIÓN}

\section{Pregunta General:}

PG. ¿Cómo afecto el Fenómeno del Niño Costero a la demanda de Limón en el corto, mediano y largo plazo luego de ocurrido el fenómeno? 


\section{Preguntas Específicas:}

PE1. ¿Cómo varió la elasticidad de la demanda de Limón en el periodo del Fenómeno del Niño Costero?

PE2. ¿Existe alguna diferencia significativa en la elasticidad de la demanda del Limón según precio mayorista y chacra?

PE3. ¿Cuánto afecto la variación del precio del Limón en los IPC durante el periodo del Fenómeno del Niño Costero?

\section{METODOLOGÍA DE RECOLECCIÓN DE LA INFORMACIÓN}

Es importante antes de empezar con la recolección de datos definir el periodo de estudios; para eso se utilizaron diferentes fuentes de información encontradas en la red que hablan sobre el Fenómeno del Niño Costero. El Servicio Nacional de Meteorología e Hidrología del Perú (Senamhi) el Fenómeno del Niño costero tuvo su mayor impacto en febrero del 2017, siendo principalmente afectados los departamentos de la costa norte peruana como: Tumbes, Piura, Lambayeque, La Libertad y Ancash (Senamhi, 2018). Si bien este fenómeno empezó en febrero tuvo una implicancia en los precios del Limón desde marzo hasta mayo del 2017 y una implicancia en la producción, desde marzo hasta octubre del mismo año. Es importante resaltar que el trabajo de investigación toma en consideración 3 escenarios: De corto plazo, de mediano plazo y de largo plazo $^{1}$. El escenario de corto plazo está compuesto por los 3 meses siguientes a ocurrido el evento (marzo 2017 - mayo 2017), el mediano plazo está compuesto por los 6 meses siguientes a ocurrido el evento (marzo 2017 - agosto 2017) y finalmente el largo plazo está compuesto por 9 meses antes y 9 meses después de ocurrido el evento (Julio 2016 - diciembre 2017).

Los datos con los cuales el presente trabajo de investigación podrá corroborar los objetivos se obtuvieron a través de diversas fuentes. Las principales fuentes

\footnotetext{
${ }^{1}$ La definición de los escenarios no es de manera arbitraria, se utiliza las elasticidades para establecer el corto mediano y largo plazo. Para un análisis más detallado de las elasticidades ver capítulo 5 y 7 , Metodología de Análisis de la Información y Análisis y Discusión de Resultados.
} 
estadísticas a utilizar son el Instituto Nacional de Estadística e Informática (Inei), el Ministerio de Agricultura y Riego (Minagri). También es importante mencionar que para contextualizar el entorno vivido por el Fenómeno del Niño se utilizó diversas fuentes. Las fuentes institucionales del Estado Peruano que el trabajo de investigación ha utilizado, y a citado adecuadamente, son las siguientes: Convención Nacional del Agro Peruano (Conveagro), Instituto Nacional de Defensa Civil (Indeci), Autoridad para la Reconstrucción con Cambios (ARCC), Servicio Nacional de Sanidad Agraria (SENASA). Así mismo cabe resaltar las fuentes privadas que el trabajo ha utilizado provienes en su mayoría de Diarios locales que cubrían la coyuntura del Fenómeno del Niño, estás son: Diario el Comercio, Diario Gestión, Diario la República, entre otros diarios locales.

Los datos que se obtuvieron del Inei son el Índice de Precios al Consumidor (IPC), de los Boletines de Variación de los Indicadores de Precios de la economía para el periodo en estudio Julio 2016 a Diciembre 2017. Por otra parte, del Ministerio de Agricultura se utilizó el Sistema Integrado de Estadísticas Agrarias (SIEA), donde se pudo obtener el precio de chacra (en Nuevos Soles por Kilogramo) y el precio mayorista (Nuevos Soles por kilogramo). La data obtenida de los precios se obtuvo del Anuario Estadístico de los Productos Agrícolas, los Boletines Mensuales de los productos agrícolas y el Boletín sobre el Limón. Toda la data obtenida para la investigación se aprecia en la tabla 4.1.

De esta tabla se desprende en el caso del IPC del limón, los meses que obtuvieron mayor variación en el precio se dieron en marzo con un $116.40 \%$ en pleno fenómeno del niño y el otro periodo se dio en los meses de Julio y Agosto con un alza de $105.03 \%$ y $133.00 \%$ respectivamente, los últimos debido a los daños sufridos en las tierras de cultivo lo que generó una menor producción.

De igual manera se ve en la presente tabla 4.1 que los meses de menor producción fueron marzo con una disminución en la producción de aproximadamente 3,000 toneladas de limón con respeto al mes anterior. Por otro lado el comportamiento de los siguientes tres meses la producción creció mas no recupero el nivel de febrero. A partir de junio hasta noviembre del 2017 la producción cae debido a que el limón es un producto estacional teniendo picos en los meses de verano. 
Tabla 4.1

Datos del índice de precios del limón, su producción y los precios en chacra y mayorista

\begin{tabular}{|l|l|l|l|l|l|}
\hline Año & Mes & $\begin{array}{l}\text { IPC: } \\
\text { Limón }\end{array}$ & Producción & $\begin{array}{l}\text { Precio } \\
\text { Chacra } \\
\mathbf{x} \text { Kg) }\end{array}$ & $\begin{array}{l}\text { Precio } \\
\text { Mayorista } \\
\text { (S/ } \mathbf{x} \text { Kg) }\end{array}$ \\
\hline 2016 & Julio & $2.30 \%$ & 18,900 & 0.8 & 3.65 \\
\hline 2016 & Agosto & $-1.14 \%$ & 16,500 & 1.03 & 3.63 \\
\hline 2016 & Setiembre & $9.40 \%$ & 18,100 & 1.20 & 3.97 \\
\hline 2016 & Octubre & $-4.80 \%$ & 20,400 & 0.80 & 3.78 \\
\hline 2016 & Noviembre & $2.10 \%$ & 21,600 & 0.68 & 3.57 \\
\hline 2016 & Diciembre & $2.60 \%$ & 16,900 & 0.80 & 3.58 \\
\hline 2017 & Enero & $3.40 \%$ & 18,291 & 0.75 & 3.69 \\
\hline 2017 & Febrero & $0.80 \%$ & 19,559 & 0.77 & 3.72 \\
\hline 2017 & Marzo & $116.40 \%$ & 16,589 & 0.79 & 8.05 \\
\hline 2017 & Abril & $-48.40 \%$ & 18,876 & 0.71 & 4.15 \\
\hline 2017 & Mayo & $-25.10 \%$ & 17,794 & 0.63 & 3.11 \\
\hline 2017 & Junio & $-2.30 \%$ & 15,087 & 0.89 & 3.04 \\
\hline 2017 & Julio & $105.03 \%$ & 8,603 & 2.40 & 6.23 \\
\hline 2017 & Agosto & $133.00 \%$ & 6,373 & 5.09 & 14.51 \\
\hline 2017 & Setiembre & $-3.90 \%$ & 5,533 & 4.20 & 13.94 \\
\hline 2017 & Octubre & $-40.80 \%$ & 6,658 & 2.76 & 8.25 \\
\hline 2017 & Noviembre & $-34.50 \%$ & 12,102 & 1.22 & 5.41 \\
\hline 2017 & Diciembre & $-33.60 \%$ & 21,939 & 0.59 & 3.59 \\
\hline
\end{tabular}

Fuente: Índice de Precios - Instituto Nacional de Estadística e Informática y Serie de

Estadísticas de Producción Agrícola - Ministerio de Agricultura y Riego

Por otra parte al realizar una comparación de precios entre lo que se paga al agricultor y lo que se paga al mayorista, se evidencia una diferencia significativa, donde el gran perjudicado es el agricultor debido a que el mayor beneficiado es el mayorista y los intermediarios, para contrarrestar esto el Estado y los Gobiernos Regionales deberían aplicar políticas y medidas donde los grandes beneficiados sean los agricultores como por ejemplo crear zonas de abastos donde ellos podrían negociar 
directamente sus productos a los grandes mercados del país, principalmente Lima Metropolitana, de esta manera se estaría reduciendo la pobreza, debido a que si los agricultores obtienen mayores ingresos las personas que trabajan en el agro verían reducida su nivel de pobreza provocando una mejora en la economía del país ya que tendrían mayores posibilidades de consumo y de invertir en una mejor educación.

\section{METODOLOGÍA DE ANÁLISIS DE LA INFORMACIÓN}

La teoría microeconómica sirve para explicar como un evento exógeno, como lo fue el Fenómeno del Niño Costero, afectó a la producción y a los precios del limón. Un desastre natural genera pérdidas en la superficie cosechada y cultivada, lo cual disminuye la producción. Por otro lado, el aumento en los precios se ve explicada por dos factores: i) menor oferta y ii) los costos de transacciones (como por ejemplo los costos de transporte) aumentan debido a la infraestructura dañada por el fenómeno del niño, lo cual hace más oneroso para los transportistas trasladar los productos de la zona norte hacia Lima metropolitana que es donde se consumen cerca del $90 \%$ de los productos agrícolas del Perú. La demanda de este bien no se mueve debido que esta depende de otros factores como ingresos, gustos o preferencias; lo cual no se vio afectado durante el Fenómeno del Niño Costero. Una representación gráfica de lo ocurrido del Fenómeno del Niño Costero en la producción y precios del Limón se ve representado en la figura 5.1 . 
Figura 5.1

Shock del fenómeno del niño en la producción y precios del limón

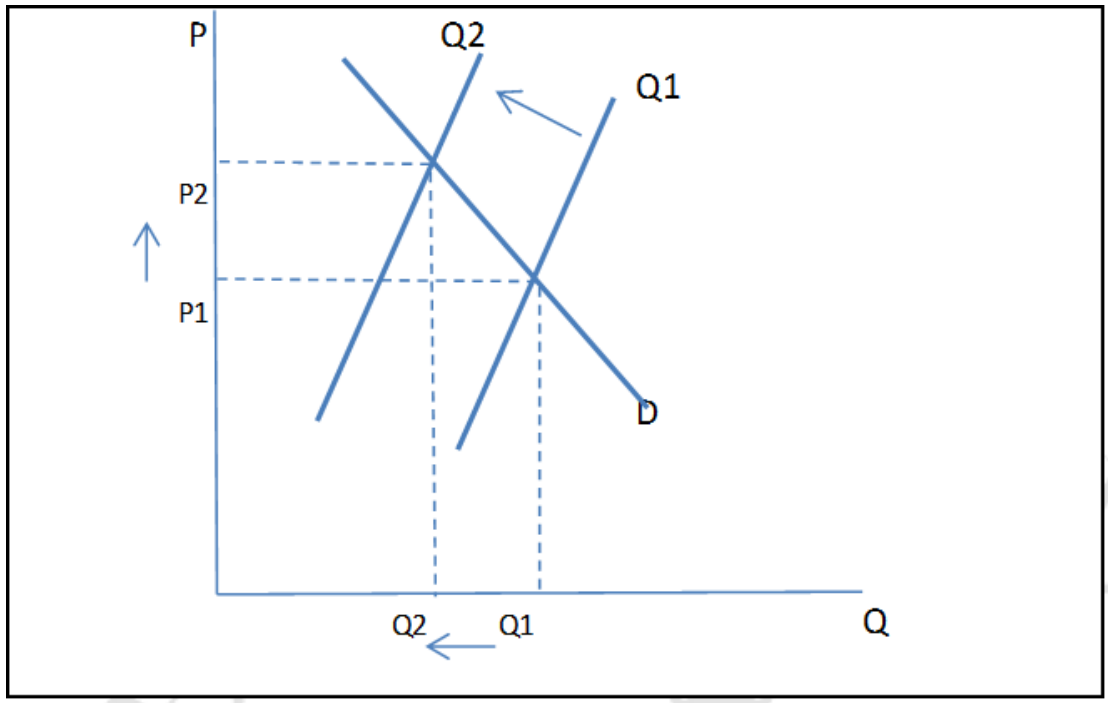

Elaboración propia

Por otro lado, para poder determinar cómo el Fenómeno del Niño Costero afectó la producción del limón se utilizan las elasticidades precio de la demanda; lo cual trata de explicar cómo cambia la cantidad demandada cuando varían los precios. Existen diferentes fórmulas para poder hablar una elasticidad precio de la demanda, el presente trabajo de investigación utiliza las 3 maneras más conocidas: simple, logarítmica y promedio.

Elasticidad Precio de la demanda (Simple):

$$
\varepsilon_{Q \times P x}=\frac{\frac{Q_{f}-Q_{I}}{Q_{I}}}{\frac{P_{f}-P_{I}}{P_{I}}}
$$

Elasticidad Precio de la demanda (Logarítmica):

$$
\varepsilon_{Q x P x}=\frac{\operatorname{LOG} 10\left(Q_{f}\right)-\operatorname{LOG} 10\left(Q_{I}\right)}{\operatorname{LOG} 10\left(P_{f}\right)-\operatorname{LOG} 10\left(P_{I}\right)}
$$




\section{Elasticidad Precio de la demanda (Promedio):}

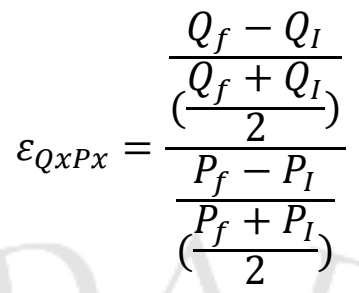

En donde, para todos los casos, $Q_{f} y Q_{I}$ es la producción final e inicial, respectivamente de limón sutil; mientras que $P_{f} y P_{I}$ es el precio final e inicial, respectivamente del mismo bien.

Utilizando valores absolutos para las formulas antes mencionadas se pueden encontrar los valores de la elasticidad precio de la demanda que pueden oscilar entre 0 e infinito, lo cual determina si el bien es inelástico o elástico. Una demanda inelástica (o perfectamente inelástica) se asocia con bienes esenciales que tienen pocos sustitutos ( $\sin$ sustitutos) lo cual genera que el consumidor sea más propenso a pagar mayores cantidades de dinero con la finalidad de que su consumo no se afecte tanto (no cambie). Por otro lado, una demanda elástica (o perfectamente elástica) se asocia con bienes no esenciales que tienen sustitutos (abundantes sustitutos) lo cual genera que el consumidor pueda escoger entre otros bienes ante un shock de precios.

Según Mankiw,N.G (2017): "La elasticidad de la demanda en un mercado depende de cómo trazamos los límites del mismo. Entre más definido sea el mercado, se tiende a tener demandas más elásticas que los mercados en un sentido más amplio, porque se vuelve más fácil encontrar sustitutos cercanos para los bienes de mercados más estrechos" (pp. 91-93). 


\section{Tabla 5.1}

Posibles resultados de la elasticidad precio de la demanda

\begin{tabular}{|l|l|}
\hline Elasticidad Precio de la Demanda & Resultado \\
\hline$\left|\boldsymbol{E}_{\boldsymbol{Q x . P \boldsymbol { x }}}\right|=\infty$ & Perfectamente Elástico \\
\hline$\left|\boldsymbol{E}_{\boldsymbol{Q x . P x}}\right|>\mathbf{1}$ & Relativamente Elástico \\
\hline$\left|\boldsymbol{E}_{\boldsymbol{Q x . P \boldsymbol { x }}}\right|=1$ & Elasticidad Unitaria \\
\hline$\left|\boldsymbol{E}_{\boldsymbol{Q x . P \boldsymbol { x }}}\right|<\mathbf{1}$ & Relativamente Inelástica \\
\hline$\left|\boldsymbol{E}_{\boldsymbol{Q x . P \boldsymbol { x }}}\right|=\mathbf{0}$ & Perfectamente Inelástica \\
\hline
\end{tabular}

De acuerdo precio de la demanda, lo cual nos permitirá analizar qué es lo que sucedió con la demanda de limón cuando aumentaron los precios en periodo del Fenómeno del Niño Costero. Los posibles resultados teóricos para nuestro análisis de la elasticidad precio de la demanda de limón se resumen en la Tabla 5.1.Sse puede apreciar que existen diferentes resultados para la elasticidad, estos están representados en las siguientes Figuras 5.2-5.6.

Figura 5.2

Demanda perfectamente inelástica: la elasticidad es igual a 0

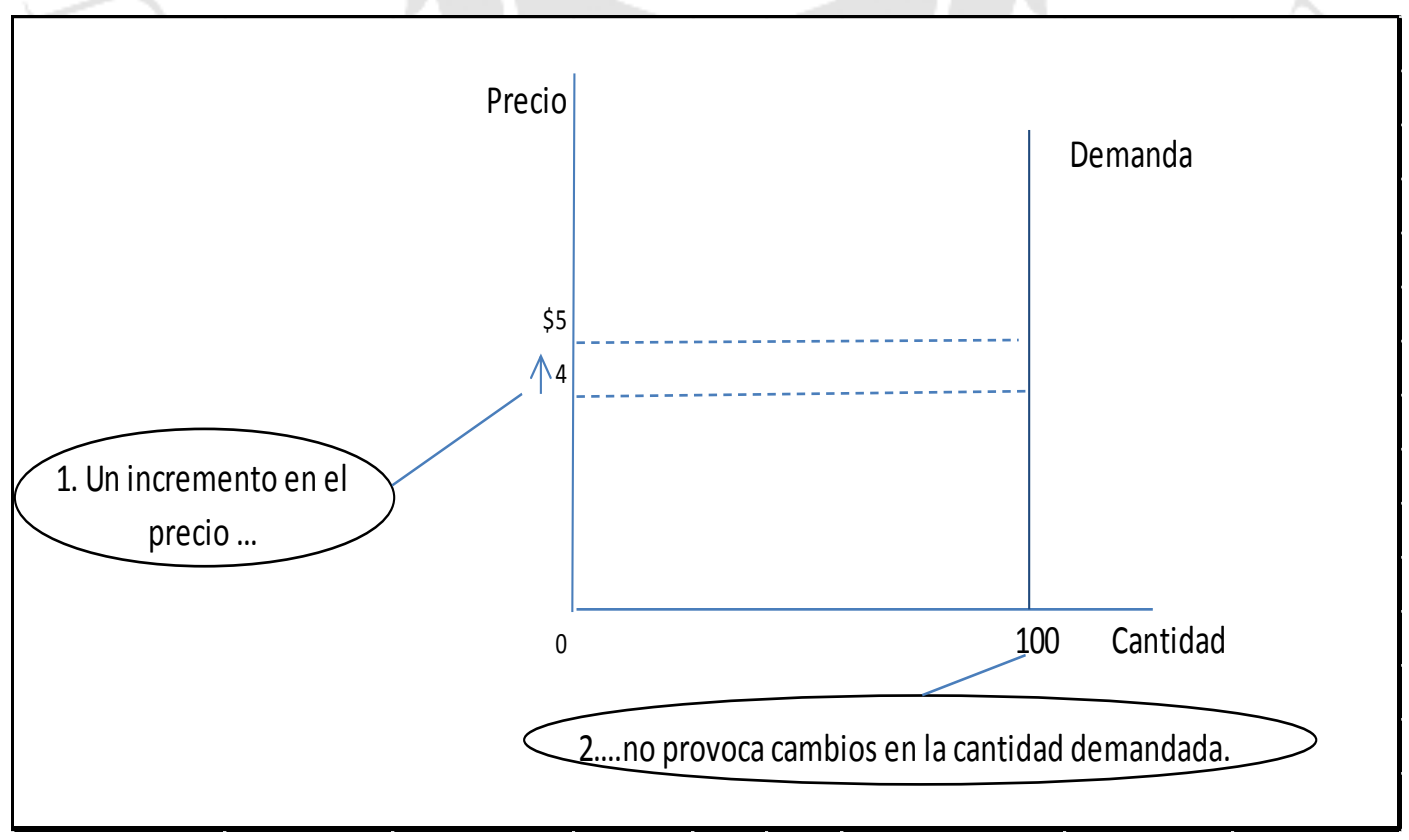

Elaboración propia 
Figura 5.3

Demanda inelástica: la elasticidad es menor que 1

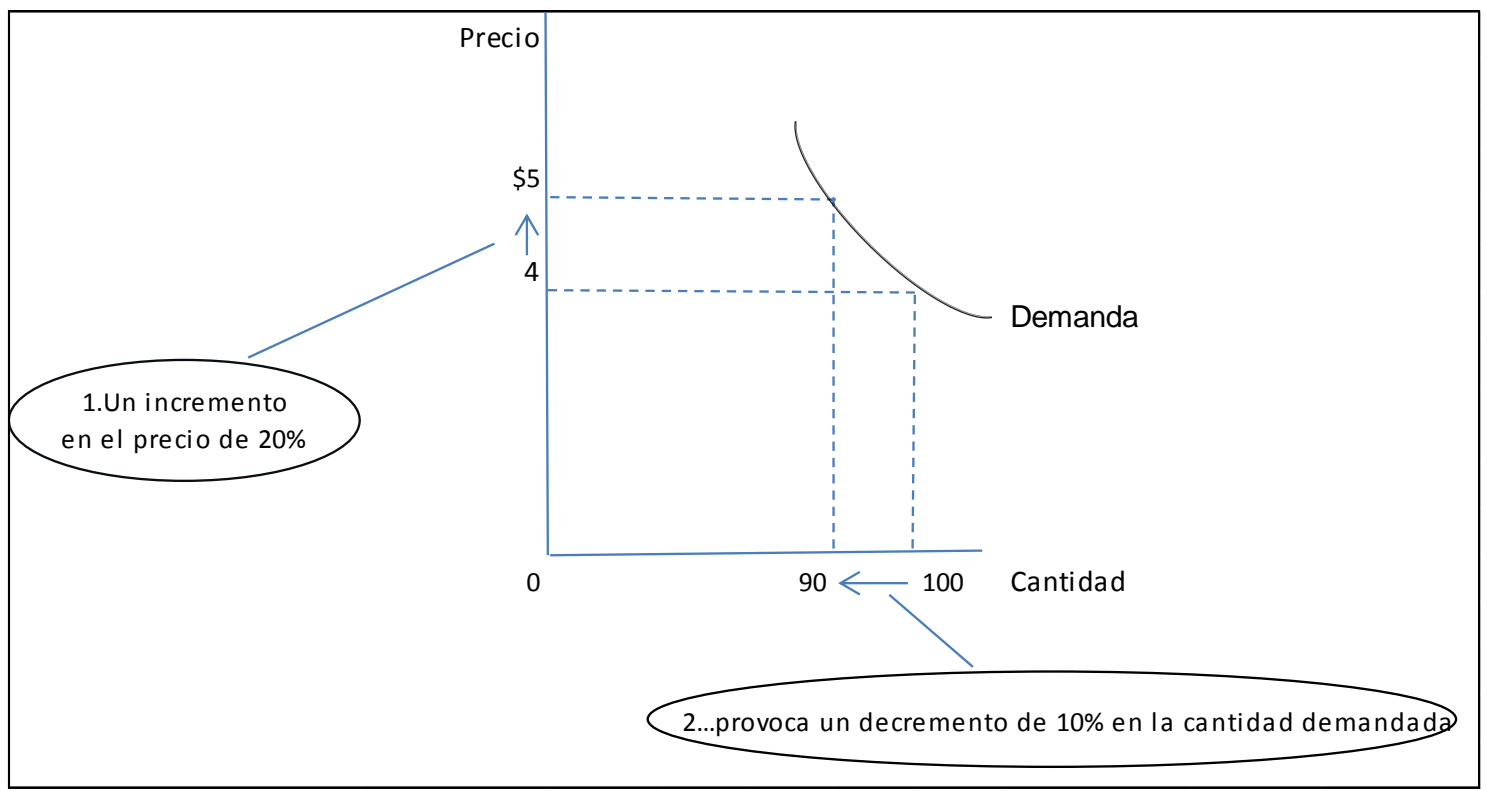

Elaboración propia

Figura 5.4

Demanda elástica unitaria: la elasticidad es igual a 1

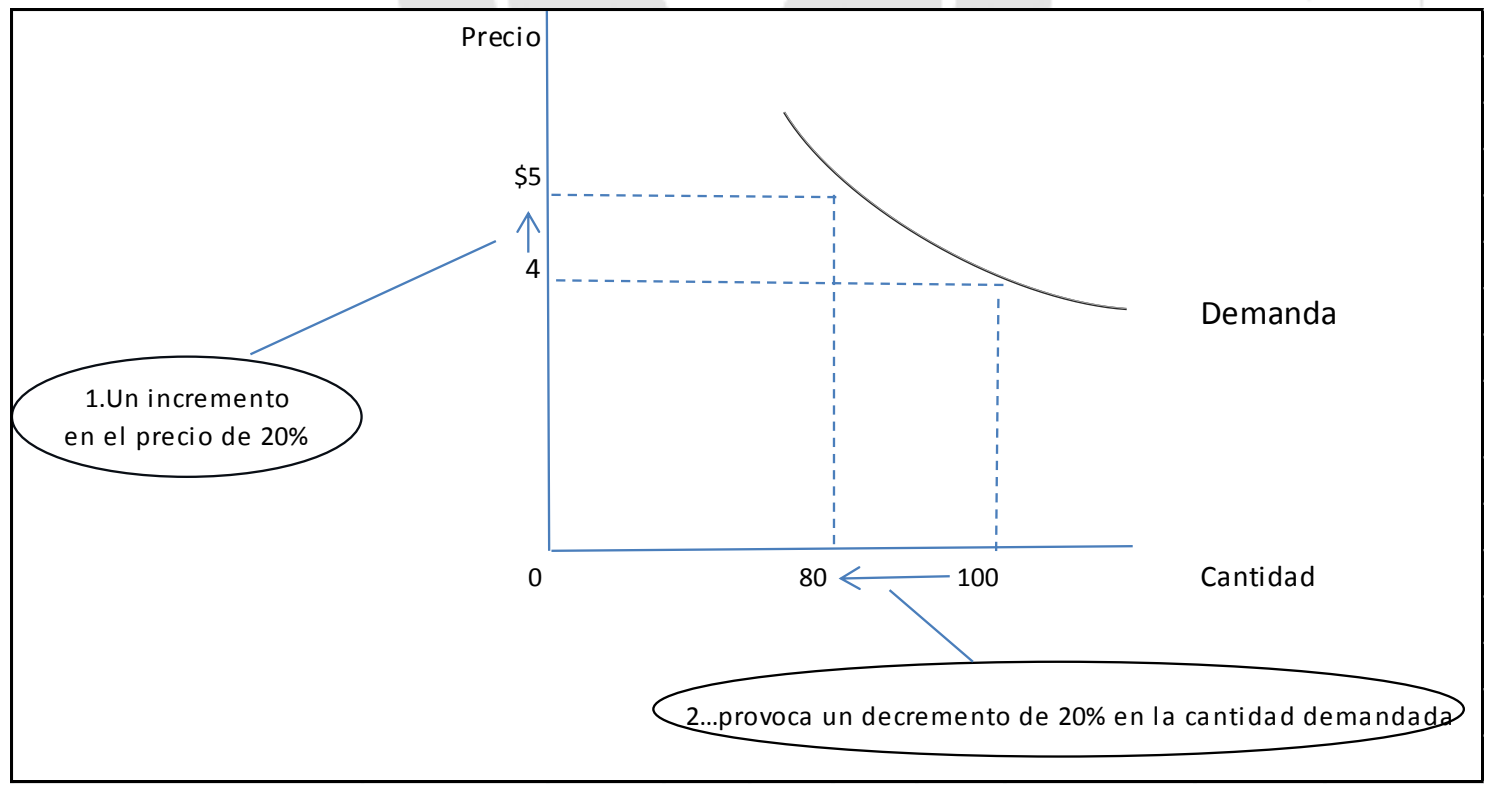

Elaboración propia 
Figura 5.5

Demanda elástica: la elasticidad es mayor que 1

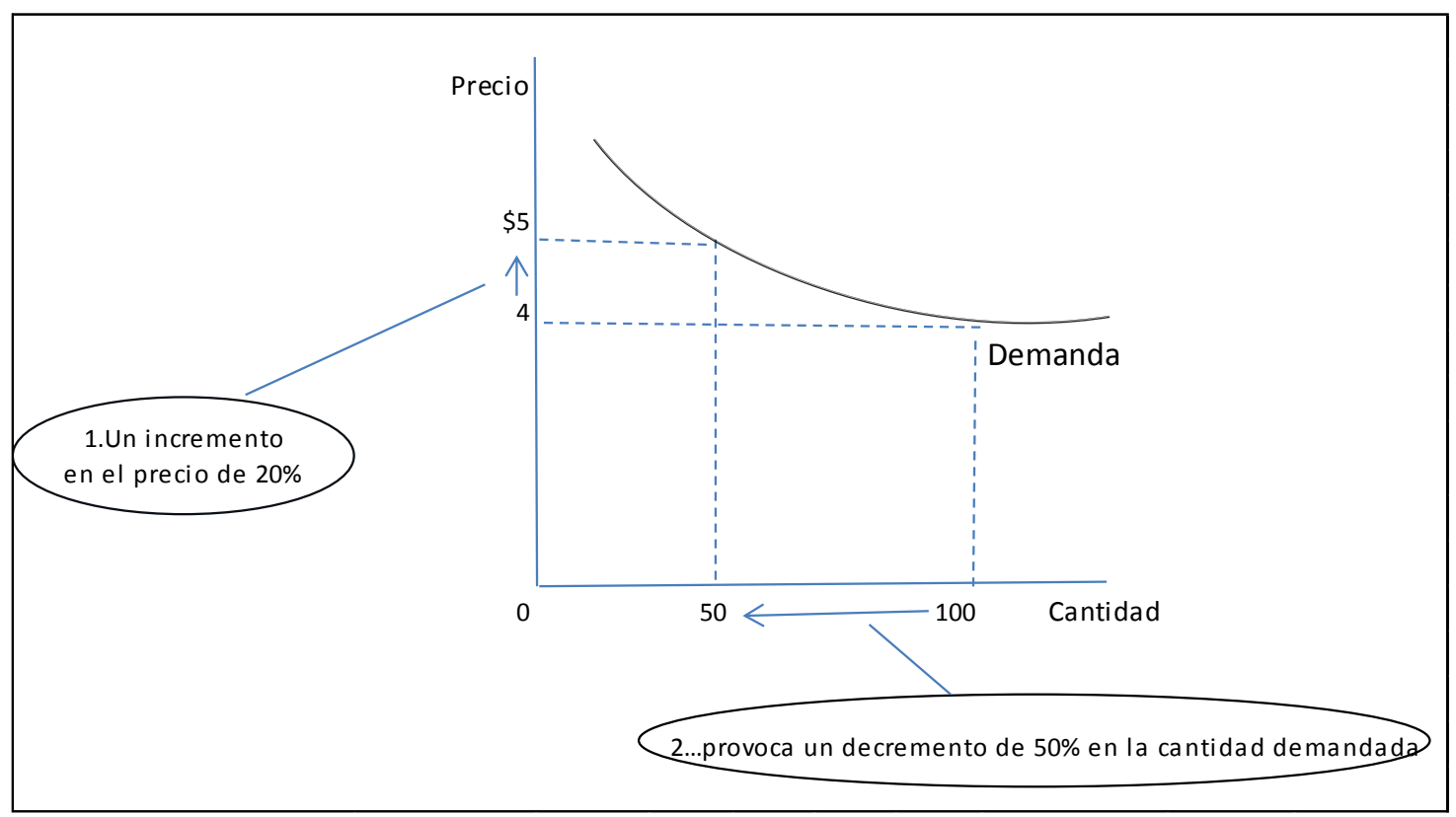

Elaboración propia

Figura 5.6

Demanda perfectamente elástica: la elasticidad es igual a infinito

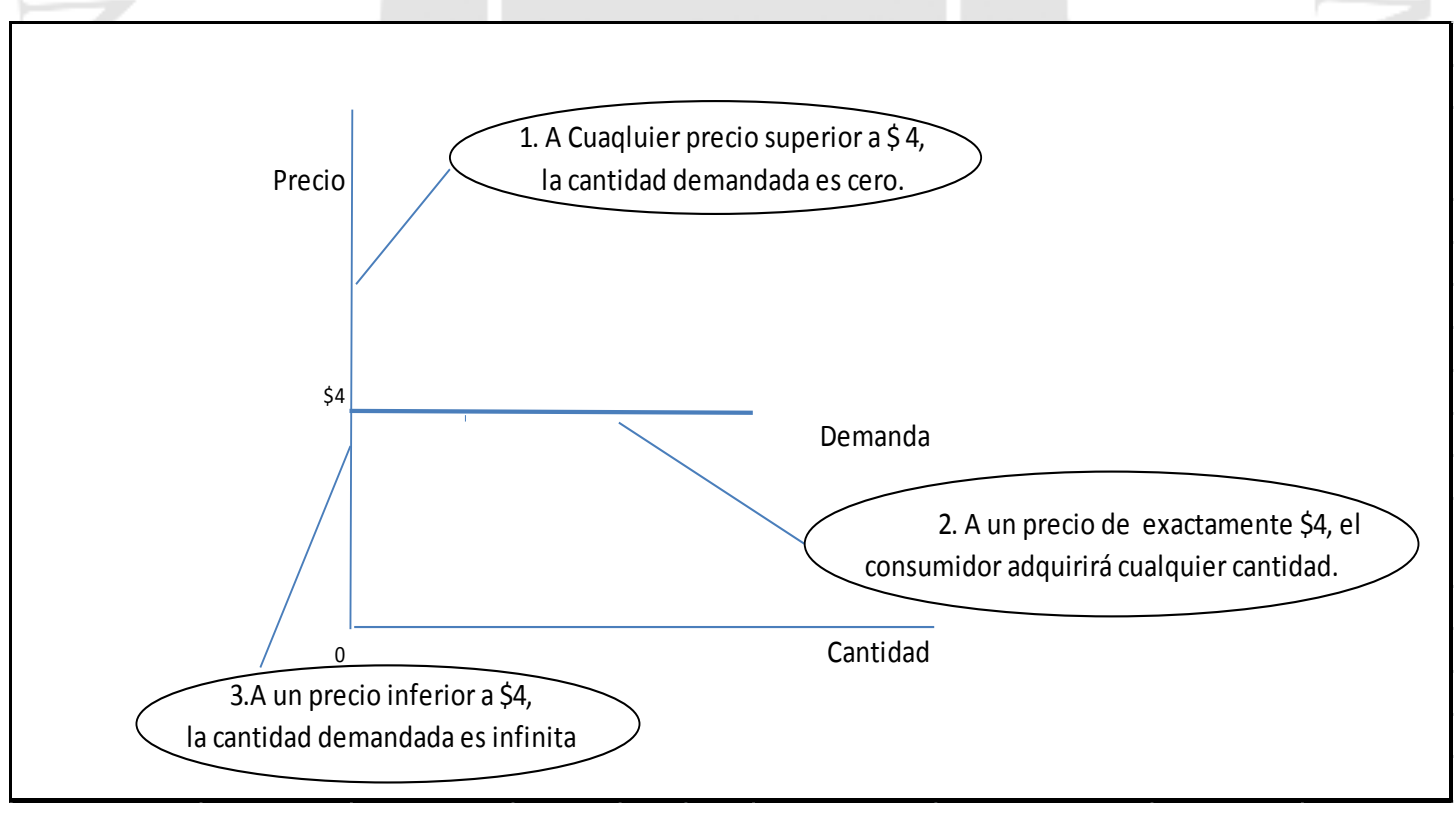

Elaboración propia

Para demostrar los efectos del fenómeno del niño en la investigación se utilizaran elasticidades para comprobar los objetivos en periodos de corto, mediano y 
largo plazo, para lo cual se van a utilizar las 3 formulas tradicionales de elasticidades para medirlas.

Es importante resaltar que el trabajo de investigación distingue entre 2 precios. El precio de chacra y el precio mayorista. Lo cual al comparar las elasticidades entre ambos (precio de chacra y precio mayorista) podríamos determinar quién es el más beneficiado: los productores o los intermediarios (ver Tabla 4.1).

\section{DESCRIPCIÓN DE CASO}

El fenómeno del Niño es una alteración en las aguas del mar específicamente en las costas del Ecuador y Perú que se inicia en el mes de diciembre, razón por la cual lleva su nombre por coincidir con las fiestas navideñas, lo que genera cambios oceanográficos, meteorológicos y biológicos, este fenómeno ejerce influencia en el comportamiento climático del planeta.

Según Rasmusson y Carpenter (1982) se tenía documentado varios eventos conocidos como "Niño Canónico", en función de su evolución temporal, es decir, cuando el calentamiento del mar se inicia en la costa peruana durante el otoño y se extiende hacia el oeste, con un máximo de calentamiento en el Pacífico central-oriental durante el verano siguiente. (pp. 354-355).

De manera local, Senamhi define al Fenómeno del Niño como un calentamientos de las aguas a lo largo de la costa peruana, el cual se origina frecuentemente pero que en ciertos años se acentúan, provocadas por las fluctuaciones entre las capas superficiales y subsuperficiales del océano. Según la metodología de Senamhi el Fenómeno del Niño Costero del 2017 tuvo categoría cálido fuerte con Índice Oceánico El Niño Mayor o Igual a +1.4. Según su metodología existen diversos categorías, los cuales vamos a describir: Cálido Fuerte con Índice ONI mayor o igual a +1.4 , cálido moderado con ONI mayor a +0.9 y menor a +1.4 , cálido débil con ONI mayor a +0.5 y menor a +1.0 , neutro con ONI mayor a +0.5 y menor a +0.5 , frio débil con ONI menor a -0.5 y menor a -0.9 , frio moderado con ONI menor a -1.0 y menor a 1.5, frio fuerte con ONI menor o igual a -15 . 
Por otra parte según investigaciones de Ashok,K y T. Yamagata (2009), sobre el Fenómeno del Niño ellos indican que existe otro patrón de anomalías en la temperatura del pacifico central el cual no llega acoplarse con el pacifico oriental, lo que constituye en otro modo de variabilidad interanual en el Pacifico tropical al cual se le denomina "Niño Modoki", donde su característica principal es su escaso efecto en las temperaturas del agua, aire y en las lluvias en la costa peruana. (pp. 461, 481-484).

Por encontrarse nuestro país en la parte septentrional del Ecuador, es propenso a sufrir periódicamente este fenómeno, debido principalmente cuando las aguas calientes del Ecuador se combinan con la corriente peruana de Humboldt lo que provoca que la temperatura superficial del agua del mar se incremente provocando una mayor condensación lo que origina precipitaciones pluviales intensas provocando aumento en los caudales de los ríos y desbordes originando pérdidas económicas tanto en la Agricultura, infraestructura y en la población de nuestro país.

En Perú los fenómenos del niño se producen con cierta frecuencia, siendo los que causaron graves daños en la economía del país (Diario Gestión, 2018), el de 1925 durante el gobierno de Augusto B. Leguía, el de 1982-1983 durante el gobierno de Fernando Belaunde con pérdidas por US\$ 3,283 millones, 1997-1998 durante el gobierno de Alberto Fujimori causo daños estimados en US\$ 3,500 millones, estos dos fenómenos representaron perdidas en el PBI anual de 1983 y 1998 del 11.6\% y 6.2\% respectivamente y el del 2017 durante el gobierno de Pablo Kuczynski las perdidas aproximadas fueron de US\$3,150 millones.

A continuación se muestra un resumen de los daños que ocasiono el fenómenos del Niño de 1997-1998 y el del 2017.

El fenómeno del niño de 1997-1998 fue el más desastroso del siglo pasado para la economía de nuestro país, a continuación se muestran las cifras obtenidas de Instituto Nacional de Defensa Civil (1998). Estos son los números: 9,608 Viviendas Destruidas, 108,000 Viviendas Afectadas, 549,000 Personas Damnificadas, 884km de Carreteras Destruidas, 6,395 km de Carreteras Afectadas, 59 Puentes Destruidos, 89 Puentes Afectados, 5 Establecimientos de Salud Destruidos, 511 Establecimientos de Salud Afectadas, 2,873 Establecimientos Educativos Afectados, 73,000 has de Áreas de Cultivo Perdidas, 131,000 has de Áreas de Cultivo Afectadas. 
Según los datos de INDECI (2017), las cifras del niño costero del 2017 son las siguientes: 285,453 personas Damnificados, 1'454,051 personas Afectados, 138 personas Fallecidas, 459 personas Heridas, 18 personas Desaparecidas, 91,906 has de Área de Cultivo Afectadas, 39,705 has de Área de Cultivo Perdidas, 63,802 Caminos Rurales Destruidos, 4,778 km de Carreteras Destruidas, 449 Puentes Destruidos, 63,802 Viviendas Destruidas, 350,181 Viviendas Afectadas, 318 Establecimientos Educativos Destruidos, 2,870 Establecimientos Educativos Afectados, 62 Establecimientos de Salud Destruidos, 934 Establecimientos de Salud Afectados .

La coyuntura del Fenómeno del Niño estuvo marcado por episodios dramáticos como calles inundadas de lodos, huaycos, derrumbe de puentes, daño a la infraestructura vial, entre otros. Como consecuencia de este fenómeno, todo esto generó una contracción en la oferta de productos agrícolas, entre ellos incluido el limón.

Es por todo esto que se escogió estudiar el efecto de la contracción de la oferta en el precio y consumo del limón en el Fenómeno del Niño 2017, tomando como base de estudio el periodo Agosto 2016 a Diciembre 2017, y además como la mayor producción del limón se produce en la regiones Piura (54.80\%), Tumbes (11.00\%) y Lambayeque (19.10\%), zonas que fueron las más afectadas por el fenómeno, lo que originó una menor cosecha, provocando una menor oferta del producto y elevando su precio, además este producto por sus características y utilización en la gastronomía peruana es poco sustituible.

Este efecto tuvo dos etapas la primera durante el fenómeno del niño marzo 2017 y la segunda durante los meses de julio y agosto como consecuencia de una reducción en la cosecha. Según el Director Regional Agraria Manuel Laberry (2017) esta fue la razón por la que el MINAGRI quiso mitigarla con la importación de limón de Ecuador y Colombia, pero detallo que el Servicio Nacional de Sanidad Agraria (SENASA) identificó que los limones de estos países estaban afectados con una mortalidad agresiva que ataca primero al fruto y luego a la planta, por lo que se prohibió su importación.

Este fenómeno del Niño del 2017, especialmente en el Norte del país provoco grandes inundaciones y daños en la infraestructura sobretodo en carreteras y puentes, lo que provocó entre otras cosas el alza en el precio del limón y de las especies marinas, según (Gestión, 2017) los restaurantes que ofrecían comida marina se vieron en la necesidad de hacer dos cosas: reducir la cantidad de pescado y de insumos o de ajustar 
directamente dicho aumento a los consumidores, con respecto a la primera alternativa, provoco una reducción de cerca del $50 \%$ en el consumo del ceviche debido a la desconfianza de los consumidores en la calidad de insumos que se estarían utilizando.

Es importante recalcar que en el año de 1999 durante el gobierno del Presidente Alberto Fujimori Fujimori el Congreso de la República aprobó la Ley de Transparencia y Prudencia Fiscal en donde se creó El Fondo de Fiscalización Fiscal (FEF) con el objetivo de acumular recursos durante las épocas de auge económico para luego poder utilizarlas en épocas de recesión solo en contingencias tales como desastres naturales y/u otros eventos exógenos. En estos casi 20 años de creado el FEF, la evolución del fondo tiene dos etapas definidas: la primera (2000-2014) es la acumulación de recursos y la segunda (2015-2017) es el uso de una parte de los fondos acumulados por parte del gobierno que cumplían con las cláusulas de contingencia del FEF. Durante esta última etapa se produjo el Fenómeno del Niño Costero motivo por el cual el directorio del FEF y la pronta reacción del gobierno central liderada por el Presidente Pedro Pablo Kuczynski autorizó la utilización de US\$ 1,869 millones del FEF para financiar los gastos de futuras obras de reconstrucción.

Luego de ocurrido el último Fenómeno del Niño, El gobierno, a finales del mes de abril, creo la Autoridad para la Reconstrucción con Cambios (ARCC) para reestructurar la infraestructura dañada por el Fenómeno del Niño nombrando como su primer Director Ejecutivo a Pablo de la Flor Belaunde, quien se encargaría de iniciar todo el proceso de reconstrucción de los daños ocasionados por el Niño Costero. Luego de 21 meses de creado el ARCC se tienen algunas estadísticas de la evolución de la reconstrucción en la zona norte del país. Según estadísticas propias del ARCC el monto que se destinó a la Autoridad para la Reconstrucción con Cambios fue de S/. 25,655 millones de soles en inversión, de los cuales el $77 \%$ se destinaria a obras de reconstrucción con cambios de la infraestructura afectada, mientras que el $21.00 \%$ se dirigirá a inversión en prevención y el $2.00 \%$ restante se orientara a capacitar en mejora de gestión de las diferentes unidades ejecutoras. 
Figura 6.1

Ejecución financiera reconstrucción con cambios a diciembre 2017

CUADRO N० 1

2017: EJECUCION FINANCIERA RECONSTRUCCION CON CAMBIOS A DICIEMBRE 2017
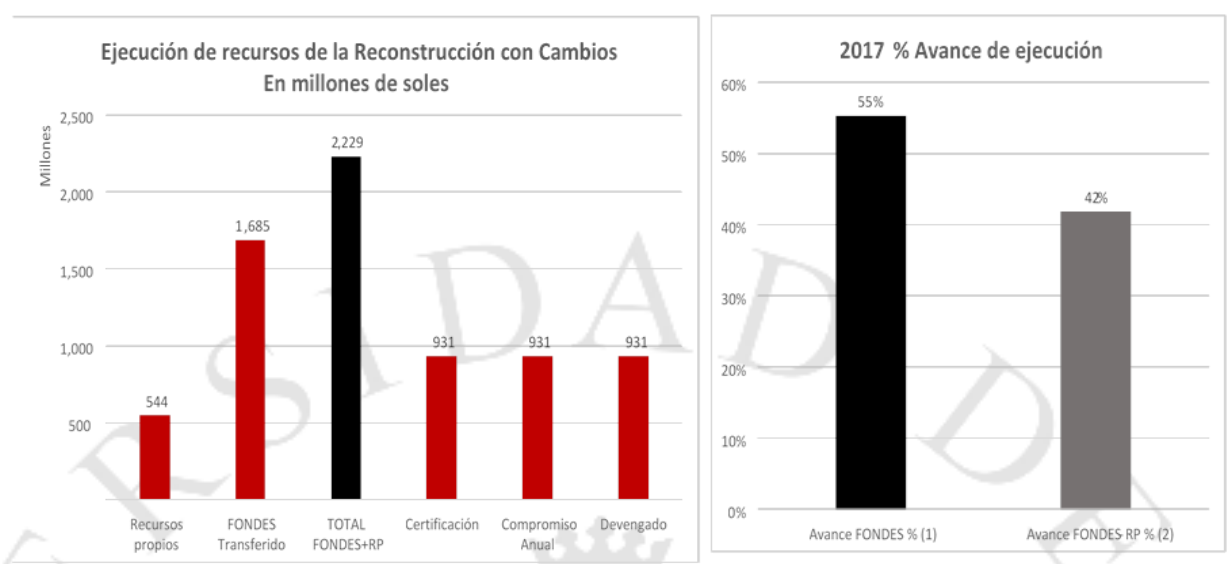

\begin{tabular}{|c|c|c|c|c|c|c|c|c|}
\hline & $\begin{array}{c}\text { Recursos } \\
\text { propios }\end{array}$ & $\begin{array}{l}\text { FONDES } \\
\text { Transferido }\end{array}$ & $\begin{array}{c}\text { TOTAL } \\
\text { FONDES+RP }\end{array}$ & Certificación & $\begin{array}{c}\text { Compromiso } \\
\text { Anual }\end{array}$ & Devengado & $\begin{array}{c}\text { Avance FONDES } \\
\%(1)\end{array}$ & $\begin{array}{c}\text { Avance FONDES- } \\
\text { RP \% (2) }\end{array}$ \\
\hline & $544,161,993$ & $1,684,553,391$ & $2,228,715,384$ & $931,474,651$ & $931,474,651$ & $931,474,651$ & $55 \%$ & $42 \%$ \\
\hline
\end{tabular}

(1) Devengado entre Total FONDES transferido.

Devengado entre Total FONDES transferido más fondos propios.

FUENTE: COnsulta amigable FONDES. Sistema de Seguimientô Análisis de ARCC

Fuente: Consulta Amigable - Ministerio de Economía y Finanzas

Figura 6.2

Distribución de lo transferido en cada sector año 2017

\section{Monto Transferido Cant. Intervenciones}

1.299 .716 .085

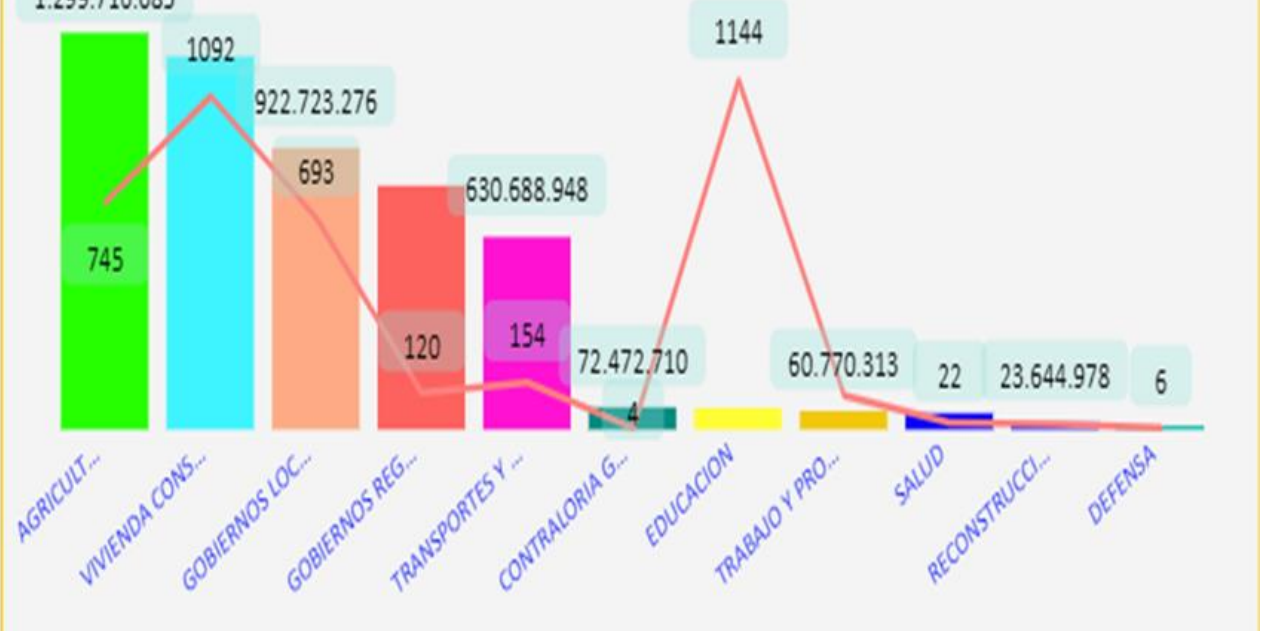

Fuente: Autoridad para Reconstrucción con Cambios

Según el Instituto crecer el monto ejecutado al 15 de Mayo del 2018 por parte de la Autoridad para la Reconstrucción con Cambios, es en reconstrucción del 3.00\% lo que 
representa S/. 597.1 millones de soles y en prevención de $22.30 \%$ representando S/. 1,214.50 millones de soles, se adjunta la información detallada en la siguiente tabla.

Tabla 6.1

Cuadro de inversión en reconstrucción al 15/05/2018

\begin{tabular}{|c|c|c|c|c|c|}
\hline \multirow[b]{2}{*}{ SECTOR } & \multirow[b]{2}{*}{$\begin{array}{l}\text { INVERSION } \\
\text { TOTAL S/. }\end{array}$} & \multicolumn{4}{|c|}{ AVANCE AL 15/05/2018 } \\
\hline & & $\begin{array}{l}\text { En } \\
\text { Ejecución }\end{array}$ & Terminado & $\begin{array}{l}\text { Total } \\
\text { S/. }\end{array}$ & $\%$ \\
\hline Agricultura & $1,344.8$ & 0.0 & 0.0 & 0.0 & $0.0 \%$ \\
\hline Educación & $2,671.5$ & 10.7 & 0.0 & 10.7 & $0.4 \%$ \\
\hline Pistas y Veredas & $1,483.5$ & 28.0 & 36.4 & 64.4 & $4.3 \%$ \\
\hline $\begin{array}{l}\text { Red Nacional } \\
\text { Carreteras }\end{array}$ & $4,245.0$ & 88.4 & 0.0 & 88.4 & $2.1 \%$ \\
\hline $\begin{array}{l}\text { Red Subnacional - } \\
\text { Caminos }\end{array}$ & $4,503.9$ & 0.0 & 0.0 & 0.0 & $0.0 \%$ \\
\hline $\begin{array}{l}\text { Red Subnacional - } \\
\text { Puentes }\end{array}$ & 923.5 & 63.0 & 69.2 & 132.2 & $14.3 \%$ \\
\hline Salud & $1,344.9$ & 0.0 & 0.0 & 0.0 & $0.0 \%$ \\
\hline Saneamiento & $2,040.6$ & 52.0 & 5.3 & 57.3 & $2.8 \%$ \\
\hline Viviendas & $1,113.6$ & 244.1 & 0.0 & 244.1 & $21.9 \%$ \\
\hline TOTAL & $19,671.3$ & 486.2 & 110.9 & 597.1 & $3.0 \%$ \\
\hline
\end{tabular}

Fuente: Instituto Crecer año 2017 - 2018 
Tabla 6.2

Cuadro de inversión en prevención al 15/05/2018

\begin{tabular}{|c|c|c|c|c|c|}
\hline \multirow[b]{2}{*}{ Departamento } & \multirow[b]{2}{*}{$\begin{array}{l}\text { Inversión } \\
\text { Total S/. }\end{array}$} & \multicolumn{4}{|c|}{ Avance al 15/05/208 } \\
\hline & & $\begin{array}{l}\text { En } \\
\text { Ejecución }\end{array}$ & Terminado & $\begin{array}{l}\text { Total } \\
\text { S/. }\end{array}$ & $\%$ \\
\hline Ancash & 195.4 & 69.1 & 20.6 & 89.7 & $45.9 \%$ \\
\hline Ica & 258.0 & 0.0 & 20.1 & 20.1 & $7.8 \%$ \\
\hline La Libertad & 642.2 & 103.1 & 50.2 & 153.3 & $23.9 \%$ \\
\hline |Lambayeque & $1,032.6$ & 11.6 & 111.1 & 122.7 & $11.9 \%$ \\
\hline $2+2$ & 332.2 & 69.6 & 41.6 & 111.2 & $33.5 \%$ \\
\hline Piura & $1,844.6$ & 224.2 & 384.0 & 608.2 & $33.0 \%$ \\
\hline Tumbes & 413.3 & 1.3 & 102.4 & 103.7 & $25.1 \%$ \\
\hline Resto & 154.6 & 0.0 & 5.7 & 5.7 & $3.7 \%$ \\
\hline Fondo Adicional & 573.5 & 0.0 & 0.0 & 0.0 & $0.0 \%$ \\
\hline TOTAL & $5,446.4$ & 478.9 & 735.7 & $1,214.6$ & $22.3 \%$ \\
\hline
\end{tabular}

Fuente: Instituto Crecer año 2017 - 2018

Los pronósticos dados por Servicio Nacional de Meteorología e Hidrología (Senamhi,2018), la probabilidad de desarrollarse un evento como el Fenómeno del Niño en el Pacifico Oriental, que incluye la costa norte del Perú alcanzan una probabilidad de $62 \%$ de ocurrencia (53\% en la magnitud Niño Débil, seguida de una magnitud neutra de $37 \%$ ) durante el primer semestre del 2019, de no llegarse a producir habrá lluvias entre lo normal y fuera de lo normal, es por eso que tanto los Gobiernos Regionales como el Gobierno Central y la Autoridad para la Reconstrucción hagan los trabajos de reforzamiento de las riveras de los ríos, reforzar los diques y canales de regadío, al igual que los puentes. Así mismo reubicar aquellas familias que tienen construidas sus viviendas en los cauces naturales de los ríos y quebradas para evitar pérdidas humanas, así como también una mayor pérdida económica para el país. La solución, quizá, radicaría en tener políticas públicas que puedan prevenir o apaciguar las implicancias del Fenómeno del Niño y no políticas públicas post efecto. Si Senamhi argumenta que la probabilidad de un fenómeno para el 2019 este en un 62\% es necesario que los hacedores de políticas públicas piensen en una visión preventiva que paliativa. 


\section{ANÁLISIS Y DISCUSIÓN DE RESULTADOS}

De los resultados obtenidos una vez realizadas las elasticidades tanto en el precio de chacra como en el precio mayorista, se adjunta la siguiente tabla:

Tabla 7.1

Resultados de elasticidades

\begin{tabular}{|c|c|c|c|c|c|c|c|}
\hline & & & & Elasti & cidades & & \\
\hline & Tipo: & Simple & & Log-Log & & Promedio & \\
\hline AÑO & MES & $\begin{array}{l}\text { Elasticidad } \\
\text { Precio } \\
\text { (Chacra) de } \\
\text { la demanda }\end{array}$ & $\begin{array}{l}\text { Elasticidad } \\
\text { Precio } \\
\text { (Mayorista) } \\
\text { de la } \\
\text { demanda }\end{array}$ & $\begin{array}{l}\text { Elasticidad } \\
\text { Precio } \\
\text { (Chacra) de } \\
\text { la demanda }\end{array}$ & \begin{tabular}{|l} 
Elasticidad \\
Precio \\
(Mayorista) \\
de la \\
demanda
\end{tabular} & $\begin{array}{l}\text { Elasticidad } \\
\text { Precio } \\
\text { (Chacra) de } \\
\text { la demanda }\end{array}$ & \begin{tabular}{|l} 
Elasticidad \\
Precio \\
(Mayorista) \\
de la \\
demanda
\end{tabular} \\
\hline 2016 & Julio & - & $-\quad=1$ & $-=$ & - & - & - \\
\hline 2016 & Agosto & -0.44 & 23.17 & -0.54 & 24.72 & -0.54 & 24.68 \\
\hline 2016 & Setiembre & 0.59 & 1.04 & 0.61 & 1.03 & $\begin{array}{ll}0.61 \\
\end{array}$ & 1.03 \\
\hline 2016 & Octubre & -0.38 & -2.66 & -0.30 & -2.44 & -0.30 & -2.44 \\
\hline 2016 & Noviembre & -0.39 & -1.06 & -0.35 & -1.00 & -0.35 & -1.00 \\
\hline 2016 & Diciembre & -1.23 & -77.68 & -1.51 & -87.72 & -1.51 & -87.29 \\
\hline 2017 & Enero & -1.36 & 2.68 & -1.27 & 2.61 & -1.27 & 2.61 \\
\hline 2017 & Febrero & 3.58 & 8.53 & 3.49 & 8.28 & 3.49 & 8.27 \\
\hline 2017 & Marzo & -5.08 & -0.13 & -5.59 & -0.21 & -5.58 & -0.22 \\
\hline 2017 & Abril & -1.39 & -0.28 & -1.23 & -0.19 & -1.23 & -0.20 \\
\hline 2017 & Мayo & 0.48 & 0.23 & 0.46 & 0.20 & 0.46 & 0.21 \\
\hline 2017 & Junio & -0.36 & 6.61 & -0.47 & 7.09 & -0.48 & 7.08 \\
\hline 2017 & Julio & -0.25 & -0.41 & -0.56 & -0.78 & -0.59 & -0.79 \\
\hline 2017 & Agosto & -0.23 & -0.19 & -0.40 & -0.35 & -0.41 & -0.37 \\
\hline 2017 & Setiembre & 0.75 & 3.38 & 0.74 & 3.55 & 0.74 & 3.55 \\
\hline 2017 & Octubre & -0.59 & -0.50 & -0.44 & -0.35 & -0.44 & -0.36 \\
\hline 2017 & Noviembre & -1.47 & -2.37 & -0.73 & -1.41 & -0.75 & -1.39 \\
\hline 2017 & Diciembre & -1.57 & -2.42 & -0.82 & -1.45 & -0.83 & -1.43 \\
\hline
\end{tabular}

Fuente: Ministerio de Agricultura, 2016, 2017

Elaboración propia 
El objetivo 1 del presente trabajo de investigación se puede determinar a través de las elasticidades precios de la demanda. Se observa que antes del fenómeno del niño las elasticidades precio de la demanda son mayores a 1, es decir son elásticas. En otras palabras los consumidores a un mayor precio demandan menos limón, pero si vemos que en forma paulatina una vez que se inicia el fenómeno las elasticidades se vuelven inelásticas (un valor absoluto entre 0 y 1), es decir a cualquier precio que se ofrezca el limón, los consumidores van a demandar una cantidad muy parecida, es decir la cantidad demandada no variará de manera significativa. Ya en el último tramo de la presente investigación la elasticidad se vuelve nuevamente elástica, es decir a una variación en el precio los consumidores demandan menos.

En el corto plazo (marzo, abril y mayo del 2017), el Fenómeno del Niño tuvo un impacto en la elasticidad precio de la demanda del limón. En promedio este fue de 0.21 es decir ante una variación en $1 \%$ de los precios del limón la cantidad demanda solo caería en $0.2133 \%$. En el mediano plazo (entre marzo y agosto del 2017) el impacto en la elasticidad precio de la demanda del limón en promedio fue de 1.31 lo que significa que luego de 6 meses de ocurrido el Fenómeno del Niño, la elasticidad precio de la demanda se volvió elástica es decir ante cambios en el precio del limón los consumidores optaron por demandar menos de este bien. Mientras que en el largo plazo (entre marzo y diciembre del 2017) el impacto en la elasticidad precio de la demanda del limón en promedio fue de 1.65. Si se toma en cuenta todo el periodo de estudios (desde julio 2016 hasta diciembre del 2017) se puede apreciar que la elasticidad precio de la demanda es de 7.84; es decir el limón es considerado como un bien elástico; sin embargo, en el corto plazo, y luego de ocurrido el Fenómeno del Niño Costero, este se volvió un bien inelástico, siendo indispensable para los consumidores y con pocos sustitutos, llegando a pagar cifras muy altas y viendo reducido su demanda en poco.

El objetivo 2 se puede corroborar a través de la comparación con las diferentes fórmulas de las elasticidades que se han tomado para la presente investigación. Se observa que la diferencia entre las elasticidades del precio en chacra con el precio mayorista es como consecuencia de que los mayoristas, donde se encuentran también los intermediarios y transportistas, se vieron beneficiados con las ganancias durante el periodo del fenómeno del niño. En el corto plazo (marzo - mayo) de ocurrido el Fenómeno del Niño la elasticidad precio (mayorista) de la demanda fue en promedio de 0.21 ; mientras que la elasticidad precio (chacra) de la demanda fue en promedio de 
2.31. Es decir el consumidor (en este caso el mayorista) tenía poder de mercado en donde si los agricultores subían los precios, los mayoristas simplemente dejaban de comprar. Es decir se comportaba como un mercado de monopsonio, en donde los intermediarios y/o mayoristas tenían mucho poder. Las elasticidades del precio de chacra son menos elásticas que las del precio de mayorista es decir ante una variación en el precio su demanda no se ve alteradas durante el fenómeno del niño, el limón al ser un producto de la canasta básica familiar y a pesar de la subida en el precio las personas lo continuaban comprando por no tener sustitutos con sus mismas características, de igual manera se observa que en los meses posteriores al fenómeno ( Julio y Agosto 2017) las elasticidad vuelve hacer inelástica, a pesar de una nueva subida en el precio como consecuencia de la poca cosecha de dicho bien por los estragos dejado por el fenómeno del niño en las tierras cultivadas y en la floración de esta planta provocando una reducción en su producción.

Para el último objetivo del trabajo se puede apreciar que el limón se ubica en el rubro Frutas dentro del Índice de Precios al consumidor, a continuación veremos en la presente tabla 7.2, la Variación de Precios al Consumidor de Lima Metropolitana para la presente investigación que corresponde al periodo de Julio 2016 a Diciembre 2017.

En la tabla 7.2 podemos observar la ponderación del rubro frutas donde se encuentra el limón es casi el 2.00\% sobre el índice de Precios al Consumidor de Lima Metropolitana lo que representa un impacto minino en la inflación mensual, de igual forma.

Por otra parte se puede observar que no solo el limón se vio afectado durante este periodo sino también otras frutas como la naranja, melón, manzana y plátano por el poco abastecimiento, pero en mayor medida por los estragos que dejaron en el norte del país en los cultivos, dándose en dos periodos la primera con el impacto inmediato del fenómeno específicamente en el mes de marzo y el segundo durante los meses de julio y agosto por la poca producción de estos productos, otro rubro que también se vio afectado son los tubérculos y raíces siendo los que influyeron la papa, camote y yuca, de igual manera los pescados y mariscos en el caso de los choros, pampanito y bonito por un menor desabastecimiento. 
Tabla 7.2

Índice de precios al consumidor de Lima Metropolitana (Julio 2016 - diciembre 2017)

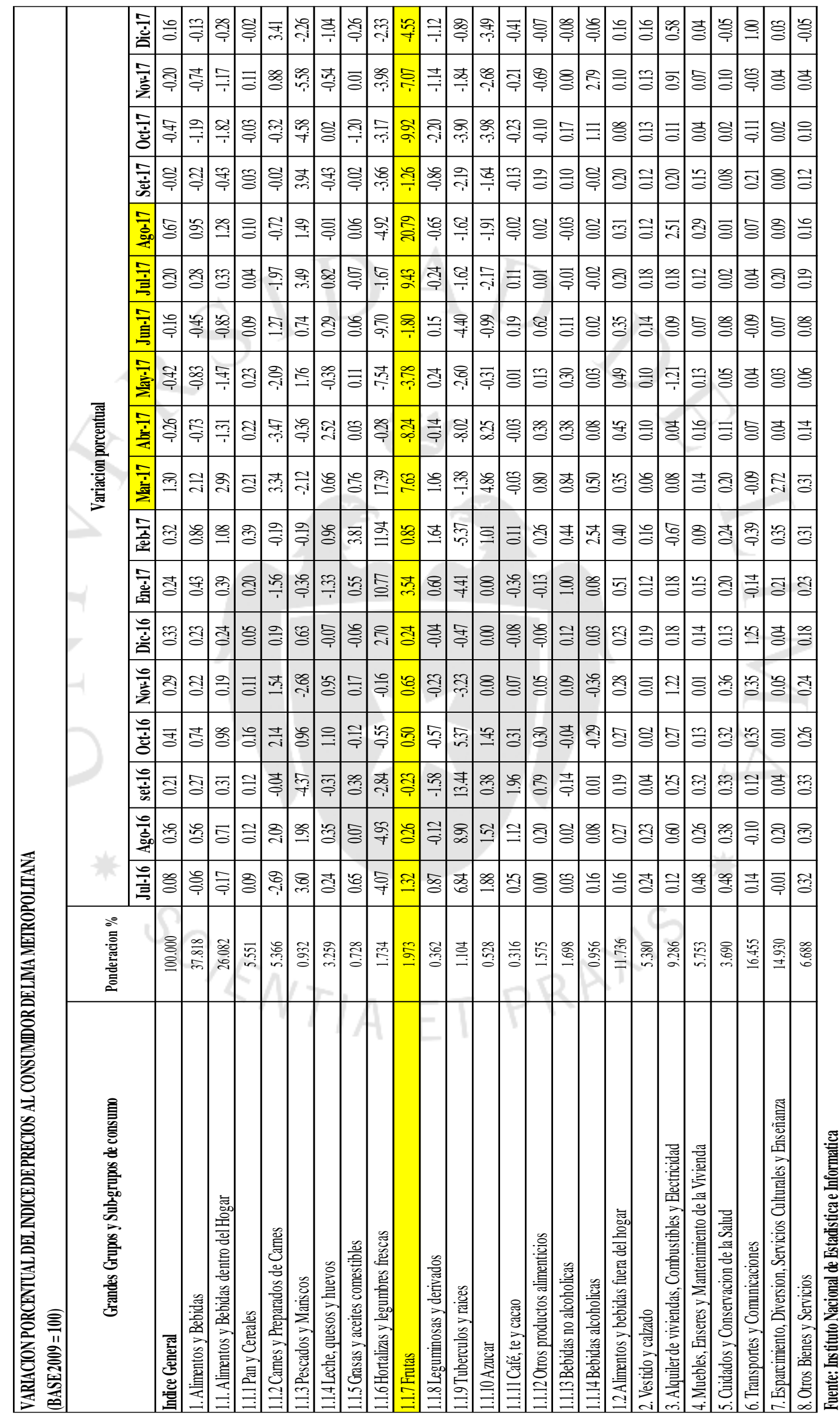


Figura 7.1

IPC y variación \% de frutas (incluido limón)

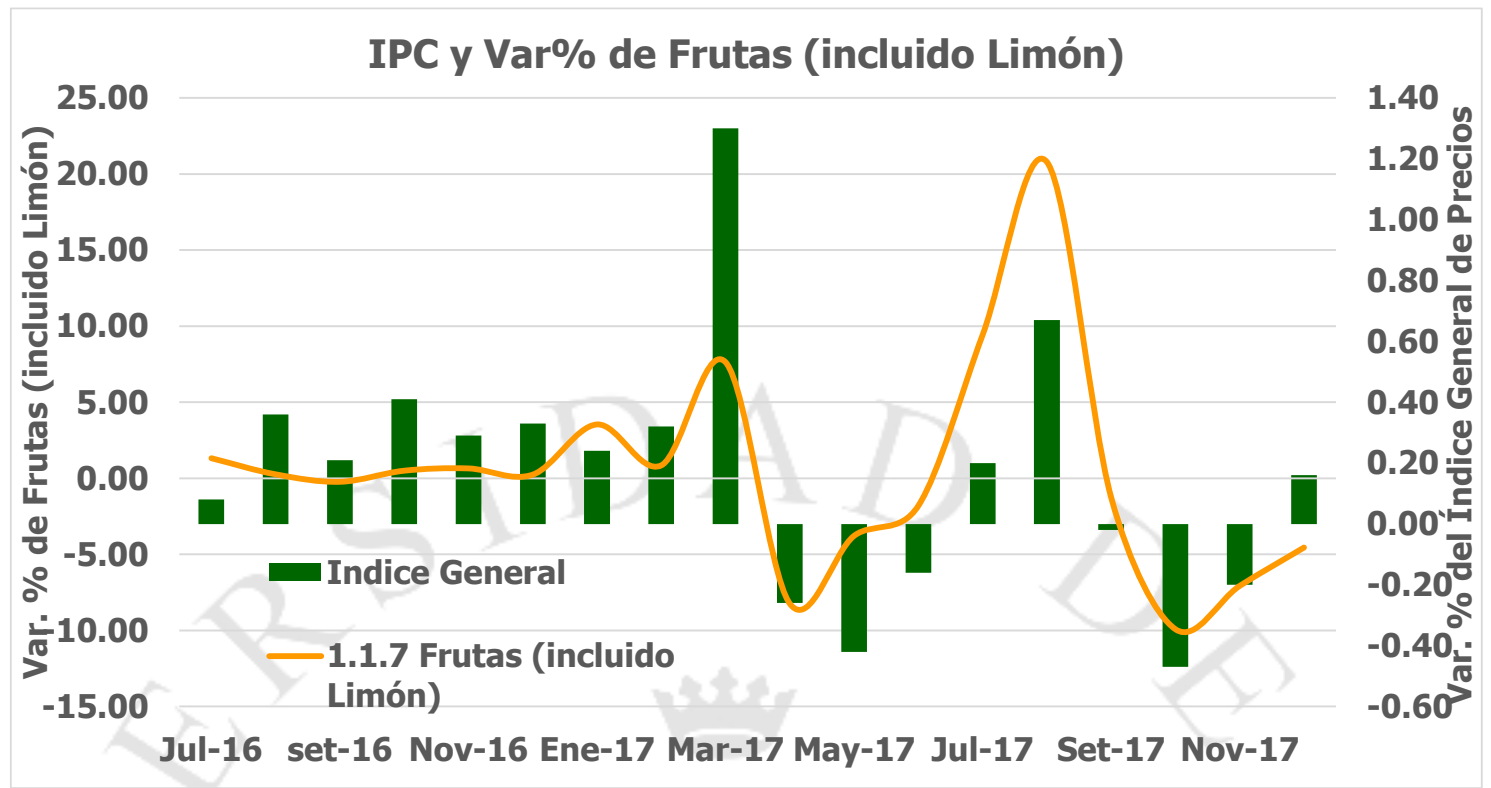

Fuente: Índice de Precios - Instituto Nacional de Estadística e Informática

Elaboración propia. Año 2016 - 2017

De la figura 7.1 y la tabla 7.2 podemos apreciar que para el mes de marzo -fecha en la cual se inició el Fenómeno del Niño Costero-el Índice de Precios al Consumidor (Índice General) llego a escalar de 0.32 en Febrero a 1.30 en Marzo, influenciado por el comportamiento de las Frutas (incluido el Limón) en 7.63\%, las hortalizas y legumbres frescas en $17.39 \%$ y alimentos y bebidas fuera del hogar en $2.99 \%$. En otras palabras, el precio del limón afecto poco al IPC en general debido a que este pesa solamente $2 \%$ del IPC; sin embargo, hubo un aumento de la inflación debido a los factores antes mencionados.

De acuerdo a nuestros objetivos trazados para la presente investigación, concluimos que en el objetivo general las elasticidades precio de la demanda del Limón son inelásticas apenas ocurrido el Fenómeno del Niño, y luego, una vez subsanados el Fenómeno, la elasticidad precio de la demanda del Limón vuelve a su tendencia elástica.

En el objetivo específico sobre las elasticidades se llega a comprobar que el efecto en el corto plazo la elasticidad es inelástica, es decir, ante la variación en el precio los consumidores seguirán comprando este productos, específicamente los restaurantes y en una menor medida las familias y en el largo plazo la elasticidad se 
vuelve elástica especialmente en el precio mayorista, lo que lleva a determinar que los productores de este producto en ningún momento se vieron beneficiados con el alza en los precios del limón. Esto queda demostrado en la tabla 7.1 donde se comprueba que al comparar las elasticidades tanto del precio de chacra como la de precio mayorista, la primera a lo largo del periodo de estudio es inelástica, es decir, a cualquier variación en el precio la demanda no se altera mientras que en la segunda la elasticidad es elástica, lo que significa que al variar el precio la demanda se dirige a otros productos.

Por último al verificar el impacto del IPC del limón sobre la inflación se observa que es mínima ya que el rubro donde se posiciona este producto tiene un peso de solamente $2.00 \%$, siendo su impacto muy insignificante, pero sin dejar de resaltar que en este fenómeno no solo se vieron elevados el precio del limón si no también otras frutas como la naranja de jugo, mango, etc. y así mismo también las legumbres, hortalizas y pescados y mariscos. Todo esto por los graves daños ocasionado por este fenómeno natural en las tierras de cultivo y en las vías de acceso, lo que provoco aumento en los precios al hacerse dificultoso el trasladar estos productos a los mercados y a la especulación de los grandes mayorista que también incidieron en la elevación de los precios. Si bien el impacto que tuvo el limón en el IPC fue mínimo, el IPC en ese mes subió debido a los otros factores que afectan los precios, no solo del limón. 


\section{RECOMENDACIONES}

Después de haber visto en la presente investigación los daños que causó el Fenómeno del Niño del 2017 en la economía del país y en forma específica el limón, el cual fue el motivo de estudio, cabe la posibilidad de recomendar lo siguiente:

1. El Estado debería estar encargado de realizar políticas públicas preventivas no paliativas en temas de choques exógenos como lo es el Fenómeno del Niño.

2. El Fondo de Estabilización Fiscal ha permitido a las autoridades subnacionales contar con los fondos monetarios necesarios para poder empezar a realizar el proceso de reconstrucción; sin embargo, debido a la coyuntura política en donde las obras públicas están inmersas en problemas de corrupción y a la baja capacidad de gasto público por la Autoridad para la Reconstrucción Con cambios, no se ha visto aun, luego de casi 20 meses de ocurrido el Fenómeno del Niño una recuperación significativa de los daños en la infraestructura peruana que generó este fenómeno, por lo cual el Estado debería agilizar o priorizar la reconstrucción de la zona costera.

3. Una importante política que debe asumir el Ministerio de Agricultura, debiera ser apoyar a los agricultores para que sean ellos los que negocien sus productos con los grandes compradores tanto de las grandes ciudades del interior del país como de Lima Metropolitana y así se vean beneficiados con el alza de los precios tal como se dio con este fenómeno del Niño y no sean solo unos pocos los que se lleven la mayor parte de los beneficios, esto generaría una reducción en la pobreza del país, debido a que si los agricultores obtuvieran mejores beneficios, se podría capacitarlos en mejores técnicas de riego y cultivo, como en conseguir mejor tecnología en provecho de sus tierras, así mismo la gente del campo que trabaja en estos cultivos se verían beneficiados con mayores ingresos tanto para ellos como para sus familias.

4. Por último, los gobiernos regionales y municipales deberían sanear los terrenos de las familias y prohibir que se construyan casas o se cultive cerca a las riberas de los ríos, para evitar pérdidas en cultivos, viviendas y vidas humanas. Esto además con lleva a provocar corrupción porque vemos que año tras año cada vez que se producen estos fenómenos naturales se producen dichas perdidas esto como 
consecuencias que las autoridades se dejan corromper para dar las facilidades de que las personas sigan construyendo en el mismo lugar donde los ríos o quebradas descargan las crecidas o los deslizamientos de tierra como consecuencia de las continuas lluvias. 


\section{REFERENCIAS}

Ashok, K., y T. Yamagata (2009). The Niño with a difference. Nature, pp. 461,481484. Nature Site.

Damnificados del Norte sin reconstrucción sin cambios. (29 de enero 2018). Diario Correo. Recuperado de https://diariocorreo.pe/edicion/la-libertad/damnificadosdel-norte-sin-reconstruccion-con-cambios-800068/

Instituto Nacional de Defensa Civil. (1998). Compendio Estadístico 1997. Lima. Recuperado de https://www.indeci.gob.pe/compend_estad/1997/6.3.fenom.pdf

Instituto Nacional de Defensa Civil. (2017). Boletín Estadístico Virtual de la Gestión Reactiva. Lima Recuperado de https://www.indeci.gob.pe/objetos/secciones/MTc=/MjI0/lista/OTk0/201708091 $\underline{\text { 706381.pdf }}$

Instituto Crecer (03 de Junio del 2018). Plan de Reconstrucción, sin muchos cambios. Diario Gestión. Recuperado de https://gestion.pe/blog/innovacion-sinergias-ycrecimiento/2018/06/plan-de-reconstruccion-sin-muchos-cambios.html

Laberry, M. (25 de julio del 2017). Fenómeno del Niño Costero afectó la producción de limones y precios suben nuevamente en los mercados. Agencia Agraria de Noticias. Recuperado de http://www.agraria.pe/noticias/fenomeno-de-el-ninocostero-afecto-produccion-de-limones-y-p-14413

Los diez fenómenos El Niño más fuertes que golpearon el Perú. (28 de marzo del 2017). Diario Gestión. Recuperado de https://gestion.pe/tendencias/diezfenomenos-nino-fuertes-golpearon-peru-131759

Macroconsult. (30 de marzo 2017). La economía peruana y los números que traen las lluvias. Diario el Comercio. Recuperado de https://elcomercio.pe/economia/economia-peruana-numeros-traen-lluvias-1$\underline{422551}$

Mankiw, G. (2017). Principios de Economía (7. a ed.). México D.F: Cengage Learning,

Ministerio de Agricultura. (2016). Boletín estadístico de producción agrícola mensual. Recuperado de http://siea.minag.gob.pe/siea/?q=publicaciones/boletinesestadisticos-2016

Ministerio de Agricultura (2017). Boletín estadístico de producción agrícola mensual. Recuperado de http://siea.minag.gob.pe/siea/?q=publicaciones/boletinesestadisticos-2017

Niño Costero: Estos son los efectos que golpearan el consumo de cebiche. (21 de marzo del 2017). Diario Gestión. Recuperado de https://gestion.pe/economia/ninocostero-son-efectos-golpearan-consumo-cebiche-131242 
Rasmusson, E. y Carpenter, T. (1982).Variations in tropical sea surface temperature and surface wind fields associated with the southern Oscillation/ El Niño. Monthly Weather Review, 110, 354-384 https://doi.org/10.1175/15200493(1982)110<0354:VITSST>2.0.CO;2

Servicio Nacional de Meteorología e Hidrología del Perú (2018) Clima Fenómeno El Niño. Recuperado de https://www.senamhi.gob.pe/?p=fenomeno-el-nino 


\section{BIBLIOGRAFÍA}

Frank, R. (2005). Microeconomía y conducta. (5a. ed.). Madrid: McGraw-Hill.

Krugman,P.R,Wells,R y Espinola,S.J.R (2015).Microeconomía. (3a. ed.). Barcelona: Reverte.

Varian, H.R. (2015). Microeconomía intermedia: Un efecto actual. (9a. ed.). Barcelona: Antoni Bosch. 


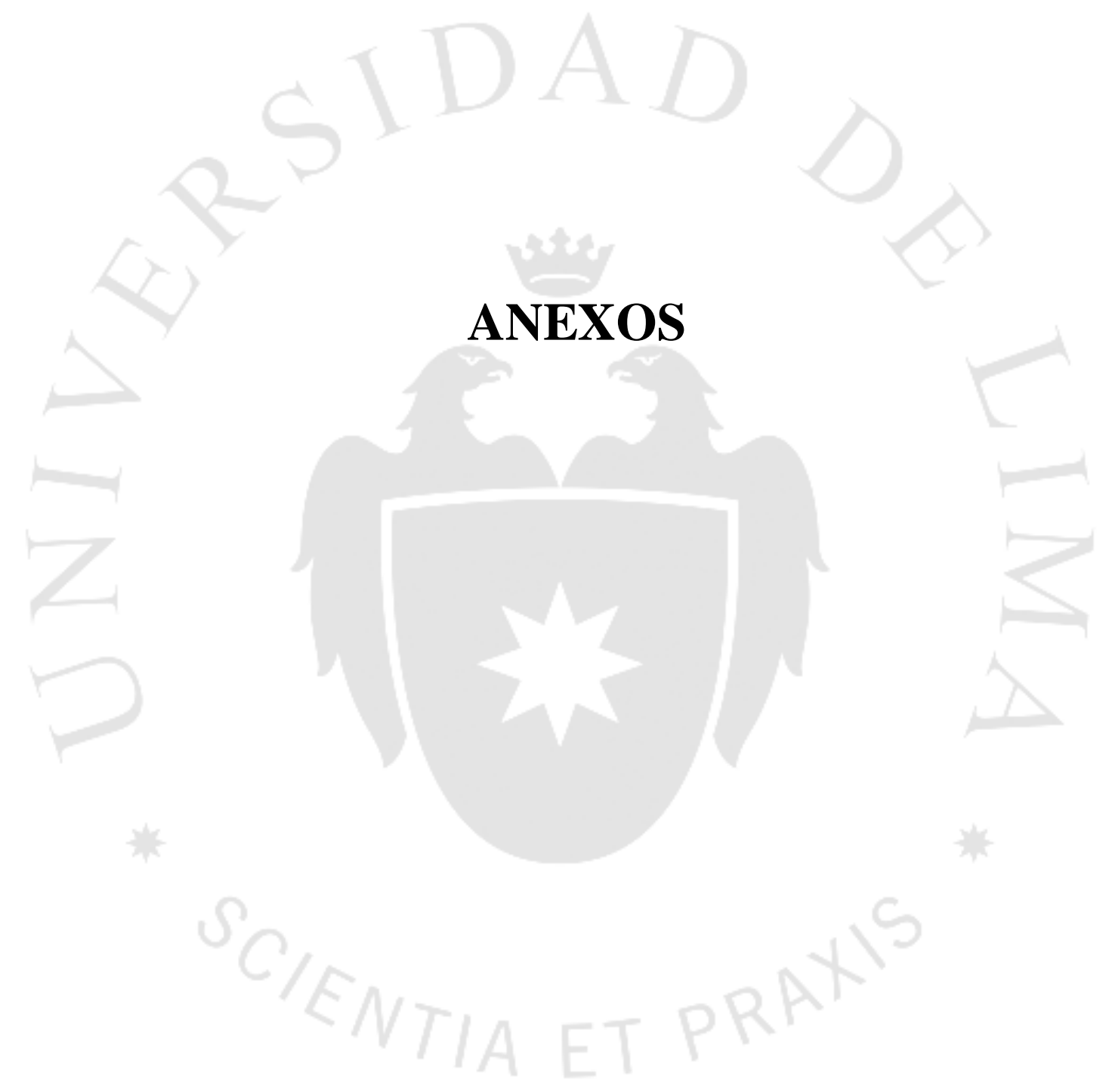


Anexo 1: Elasticidades en valores absolutos

\begin{tabular}{|c|c|c|c|c|c|c|c|}
\hline & \multirow{3}{*}{ Tipo: } & \multicolumn{6}{|c|}{ Elasticidades (En valores absolutos) } \\
\hline & & \multicolumn{2}{|c|}{ Simple } & \multicolumn{2}{|c|}{ Log-Log } & \multicolumn{2}{|c|}{ Promedio } \\
\hline & & $\begin{array}{c}\text { Elasticidad } \\
\text { Precio } \\
\text { (Chacra) de la } \\
\text { demanda }\end{array}$ & $\begin{array}{c}\text { Elasticidad } \\
\text { Precio } \\
\text { (Mayorista) de } \\
\text { la demanda }\end{array}$ & $\begin{array}{c}\text { Elasticidad } \\
\text { Precio } \\
\text { (Chacra) de la } \\
\text { demanda }\end{array}$ & $\begin{array}{c}\text { Easticidad } \\
\text { Precio } \\
\text { (Mayorista) de } \\
\text { la demanda }\end{array}$ & $\begin{array}{c}\text { Elasticidad } \\
\text { Precio } \\
\text { (Chacra) de la } \\
\text { demanda }\end{array}$ & $\begin{array}{c}\text { Easticidad } \\
\text { Precio } \\
\text { (Mayorista) de } \\
\text { la demanda }\end{array}$ \\
\hline 2016 & Julio & & & & & & \\
\hline 2016 & Agosto & 0.44 & 23.17 & 0.54 & 24.72 & 0.54 & 24.68 \\
\hline 2016 & Setiembre & 0.59 & 1.04 & 0.61 & 1.03 & 0.61 & 1.03 \\
\hline 2016 & Octubre & 0.38 & 2.66 & 0.30 & 2.44 & 0.30 & 2.44 \\
\hline 2016 & Noviembre & 0.39 & 1.06 & 0.35 & 1.00 & 0.35 & 1.00 \\
\hline 2016 & Diciembre & 1.23 & 77.68 & 1.51 & 87.72 & 1.51 & 87.29 \\
\hline 2017 & Enero & 1.36 & 2.68 & 1.27 & 2.61 & 1.27 & 2.61 \\
\hline 2017 & Febrero & 3.58 & 8.53 & 3.49 & 8.28 & 3.49 & 8.27 \\
\hline 2017 & Marzo & 5.08 & 0.13 & 5.59 & 0.21 & 5.58 & 0.22 \\
\hline 2017 & Abril & 1.39 & 0.28 & 1.23 & 0.19 & 1.23 & 0.20 \\
\hline 2017 & Mayo & 0.48 & 0.23 & 0.46 & 0.20 & 0.46 & 0.21 \\
\hline 2017 & Junio & 0.36 & 6.61 & 0.47 & 7.09 & 0.48 & 7.08 \\
\hline 2017 & Julio & 0.25 & 0.41 & 0.56 & 0.78 & 0.59 & 0.79 \\
\hline 2017 & Agosto & 0.23 & 0.19 & 0.40 & 0.35 & 0.41 & 0.37 \\
\hline 2017 & Setiembre & 0.75 & 3.38 & 0.74 & 3.55 & 0.74 & 3.55 \\
\hline 2017 & Octubre & 0.59 & 0.50 & 0.44 & 0.35 & 0.44 & 0.36 \\
\hline 2017 & Noviembre & 1.47 & 2.37 & 0.73 & 1.41 & 0.75 & 1.39 \\
\hline 2017 & Diciembre & 1.57 & 2.42 & 0.82 & 1.45 & 0.83 & 1.43 \\
\hline & & 1.19 & 7.84 & 1.15 & 8.44 & 1.15 & 8.41 \\
\hline
\end{tabular}

Fuente: Índice de Precios - Instituto Nacional de Estadística e Informática y Serie de

Estadísticas de Producción Agrícola - Ministerio de Agricultura y Riego

Elaboración: Propia. 